Research Paper:

\title{
The Effect of Coping Strategies Training on the Quality crossuark of Life of the Family Caregivers of Patients With Chronic Mental Disorders
}

\author{
Mehrnoosh Inanloo ${ }^{1}$, Fahimeh Ramezani ${ }^{1 *}$, Naimeh Seyedfatemi ${ }^{1}$, Susan Moudi ${ }^{2}$, Hamid Haghani
}

1. Department of Psychiatric Nursing, School of Nursing and Midwifery, Iran University of Medical Sciences, Tehran, Iran. 2. Department of Psychiatry, School of Medicine, Babol University of Medical Sciences, Babol, Iran.

3. Department of Biostatistics, School of Public Health, Iran University of Medical Sciences, Tehran, Iran.

ditation: Inanloo, M., Ramezani, F., Seyedfatemi, N., Moudi, S., \& Haghani, H., 2016. The Effect of Coping Strategies Training on the Quality of Life of the Family Caregivers of Patients With Chronic Mental Disorders. Journal of Client-Centered Nursing Care, 2(4), pp. 207-214. https:// doi.org/10.32598/jecnc.2.4.207

: https://doi.org/10.32598/jccnc.2.4.207

Article info:

Received: 27 Apr. 2016

Accepted: 29 Jul. 2016

Keywords:

Coping strategies, Quality of life, Family caregivers

\begin{abstract}
A B S T RA C T
Background: Caring of the patients with mental disorders is a responsibility which brings lots of pressures and stresses to family members and lowers their quality of life. The current research aimed to study the effect of training coping strategies on the quality of life of caregivers of patients with chronic mental disorders.

Methods: This study is a non-randomized clinical trial conducted on 94 caregivers of patients with chronic mental disorder. The samples were recruited by convenience sampling method and the eligible ones were put in the intervention and control groups. The data collection tool were demographics questionnaire and SF 36 life quality scale. The coping strategies were taught in eight 90-minute sessions, during 8 consecutive weeks (once a week) for 2 months in groups. The obtained data were analyzed using descriptive and inferential statistics by SPSS V. 20.

Results: The caregivers were mostly female (62.7\%) aged between 35 and 55 years. More than $80 \%$ of the study subjects were married. Most study subjects in both groups were housewives. In the intervention group, the physical functioning of quality of life before and two months after the intervention showed no significant difference $(\mathrm{P}=0.877)$, but other areas showed significant increase two months later $(\mathrm{P}<0.001)$. In the intervention group, the quality of life significantly increased two months after the intervention $(\mathrm{P}<0.001)$, but it has declined in the control group ( $\mathrm{P}$ $<0.001)$.
\end{abstract}

Conclusion: Based on study findings, coping strategies training was effective in promoting the quality of life. Experts in family health education are in need to educate and train families. Therefore, we recommend the mental health system to promote quality of life via developing such specialized programs and facilities at educational and health centers.

\footnotetext{
* Corresponding Author:

Fahimeh Ramezani, MSc.

Address: Department of Psychiatric Nursing, School of Nursing and Midwifery, Iran University of Medical Sciences, Tehran, Iran. Tel: +98 (911) 2177223

E-mail: ramezanif7@gmail.com
} 


\section{Background}

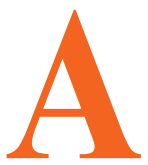

$\mathrm{t}$ the moment, about 450 million people suffer from mental or behavioral disorder across the world, i.e. at least 1 out of 4 families is afflicted with a mental or behavioral disorder. The family members are often caregivers and in charge of everything from physical and emotional supports to pay expensive treatment costs of their patients (A Group of Psychiatry Professors of Medical Universities in Iran 2010). The incidence of mental disorder has been reported $6 \%$ in Iran. Based on 75 million population of Iran, around 450000 people suffer from mental disorders in our country, and need treatment, rehabilitation services and some hospitalization (Rahgozar et al. 2012). More than $60 \%$ of the clients are discharged from mental institutions and return to their own families (Varcarolis 2002).

Proven community-oriented service emphasizes the role of family as the most important and the best social supporter of the patients with chronic mental disorder (Boyd 2005). When a family member experiences a mental disease, the family is inclined to be a great source for helping the patient. Caring a patient is already stressful but diagnosing a psychiatric disease is distressing, in particular for the family. Having a patient with mental disease in a family can create a sense of guilt based on the role of disease hereditary nature from the parents, concern about the disease prognosis and other family member's involvements. Labeling also results in the family members' embarrassment associated with others' attitude toward the family (Keltner \& Debble 2014).

Based on the evidence, family caregivers have limited data, resources and supports at hand to be prepared for such a new role (Hudson et al. 2008). Most people already lack personal experience in such cases facing with a severe mental disease in the family (Taherkhani 2012).

Family caregivers have undergone some losses such as hopes, visions and expectations and regretted because of experiencing the feelings of shock, disbelief, anger, frustration, guilt, anxiety, and shame. Family members sometimes feel being seated on an emotional roller with alternative periods of relapse and recovery. These cycles create significant distress for the family members who often experience huge distress following recovery after another relapse (Sartorius et al. 2010).

The current studies indicate that the diversity and intensity of care roles can lead to care burden and pressure in family caregivers of such patients (Navidian \& Bahari 2008; Onga 2008).

Caregivers' care burden for the patient and family is awfully problematic. Caregivers report many nuisances related to their health status and because the care burden of a disease is taken for granted and has a covert nature, the patients and their caregivers are both in pain. Caregivers are desperately in need of social support and to be perceived. About $70 \%$ of the caregivers are exposed to two great problems about the patient's treatment and adapting with care induced responsibilities (Milbury et al. 2013).

Thus family members and in particular the caregivers are highly prone to lose their quality of life due to spending time and energy for caring the patients (Glozman 2004). Caregivers face mental disorders as a direct consequence of their caring role and experience higher rates of mental problems than the general population. This leads to negative effects on their quality of life and the standard of care delivered (Rani 2012). The individuals caring the patients at homes are prone to diseases like depression and anxiety disorders and their life expectancy is 10 years lower than normal people. Also it decreases such people's life quality (Hares Abadi et al. 2012).

The negative effect of care on the caregivers' quality of life accompanies other side effects such as poor mental health, additional use of anti-depressors and increased requirement of medical and hospital care (Sartorius et al. 2010). Corring by qualitatively studying quality of life of mental patients' family members concluded that as families spend their time on caring their patients, no time is left for them to enjoy life and have recreation. Extreme frustration, stress, fear, being inconsiderate, lack of support and constant doubt are some complaints the mental patients' families stated in their quality of life evaluation (Corring 2002).

Improving the effective coping strategies results in decrease the care pressure and ultimately, promotion of caregivers' physical and mental health (Abbasi et al. 2012). For effective participation in the patient's treatment programs, the family is exposed to problem. Through presenting broader training and more supports for the families, the mental health staff can help mitigate the pressures incurred on the family and provide the patient with a more useful support system (Glynn 2000).

In addition to previous coping strategies, the nurses have to focus on other effective coping strategies that the clients overlook. The nurses take measures for providing the environmental supports and or strengthening them 
by determining the goals and priorities and decide on how to use them, i.e., which one of the coping strategies of the client needs controlling and which one requires strengthening (Kooshan \& Vaghei 2012).

Because adaptability is important in the quality of life experience, it is a critical duty for the nurses to maintain or enhance the quality of life (Pickett et al. 2005). Relevant studies indicate that family participation in mental health service improves disease prognosis and promotes adaptability and also the family members' quality of life (Boyd 2005).

As mentioned before, caring a mentally disordered sufferer is a responsibility intertwined with lots of stresses and pressures for the family members, lowering their quality of life. Some therapeutic interventions such as training, support and psychotherapy can significantly decrease burden of family caregivers. In this way, the ground for care quality increase is paved and physical and mental health of family caregivers are promoted (Navidian et al. 2010). For this purpose, the current study was conducted to outline the effect of coping strategies training on the family caregivers of the patients with chronic mental disorders. Boosting the families' academic, financial, and emotional sources can be an appropriate umbrella for the patient so that the therapeutic and rehabilitation objectives be achieved. Educating the family about the disease, transferring the required skills on how to tolerate and cope with the disease raises the family's potential capabilities and it may somewhat compensate lack of the services available for the outpatient and inpatient psychiatric facilities (Glynn 2000).

\section{Materials \& Methods}

\section{Study design and participants}

This study was a non-randomized clinical trial. This trial has been recorded at Clinical Trials Registry site (No. IRCT2015120925450N1) and verified by Iran University of Medical Science Ethics Committee holding the code IR.IUMS. REC, 1394.9211196214 on 12 October, 2015. It was conducted on caregivers of patients with chronic mental disorder referred to Shahid Yahyanejad and Ayatollah Rouhani educational and medical centers and clinics in Babol, Iran from December 2015 to April 2016. The inclusion criteria were as follows: caregivers' ages ranged $18-60$ years, able to read and write, have healthy vision and hearing, lack prior training on coping strategies, lack chronic physical and mental diagnosed disease during their caring service, no substance abuse or dependency disorder, not being in critical conditions in the past 6 months in care (severe stress, the death of immediate family member, and be responsible of caring only one physical or mental patient, also the patients' diagnoses be passed at least one year.

The exclusion criteria included being reluctant to continue receiving training and participating in the study, not participating in 2 sessions out of 8 training sessions, contributing in the similar training sessions concurrently.

To determine the required sample size with the confidence level of $95 \%$ and the power analysis of $80 \%$, and with assuming effectiveness of coping strategies training on the quality of life in family caregivers of patients with chronic mental disorder. The sample size for each group was calculated as 47 caregivers.

\section{Data collection}

In this study, the demographics questionnaire along with short-form quality of life (SF-36) questionnaire (filled in by the study samples) were used as the data collection tool.

SF-36 quality of life questionnaire includes 36 items examining 8 dimensions of physical performance, physical roleplaying, body pain, general health, vitality, social functioning, emotional roleplaying, and mental health. The quality of life has been rated based on Likert-type scale at 5 levels of "very poor," "poor," "average," "good," and "very good." The sum of the 8 mental health dimensions gets scores from 0 to100 where higher scores indicate higher quality of life. SF-36 quality of life scale reliability has been measured by Montazeri et al. (2005) and its Cronbach $\alpha$ has been reported as $0.77-0.9$. The content validity of educational booklet and demographic questionnaire was confirmed by 10 nursing professors of Iran University of Medical Sciences, Tehran, Iran.

The data were collected in two stages as before and 8 weeks after starting the intervention. In the control group, the same routine has been implemented. The sampling has been convenient and the eligible ones have been put in the intervention and control groups ( 47 subjects in the intervention group and 47 in the control group). At the time of study (from December 2015 to April 2016), the caregivers of the patients referring on odd dates to Babol based Medical Science University Clinics of Shahid Yahyanejad and Ayatollah Rouhani Centers were put in the control group and those referring on the even dates were put in the intervention group.

\section{Intervention}

In this research, by coping strategies we mean a structured program consisting of 8 training sessions with certain objectives held for 2 months, during eight weeks (once/week) 
and each session consisting of 90 minutes as groups consisting of 10 subjects in the intervention group. Each session starts with explanation of content objectives presented by lecture and slides (20 minutes), then a group discussion (50 minutes) and finally the presented materials will be summarized (20 minutes).

The coping strategies training program is based on a training pamphlet prepared and codified by the researcher after surveying the papers and library studies. In order to verify the content, it was handed to some faculty members of the School of Nursing and Midwifery, Iran University of Medical Science. The contents of the sessions are as follows: the first session, familiarity with the training contents, training program and objective explanation; the second session, explanation of psychiatric disorders schizophrenia and bipolar disorder and what are their symptoms; The third session: causes and signs of the stress as well as its effects on our life; The fourth session: coping with stress, the effective and efficient strategies in dealing with stress; The fifth session, the methods to cope with stress; the sixth session, other methods to cope with stress; the seventh session, social relation skills practice, how to get through the patient and solve the related crises, train problem solution, seek support from the mental health team; the eight session, conclusion and review of previous sessions. At the end of the sessions, the training manual is handed to the participants.

\section{Data analysis}

The data were analyzed by descriptive and inferential tests by SPSS version 20. For data analysis, descriptive statistics (frequency, percentage, mean and standard deviation) and inferential statistics to determine significance (Chi-Square, T-Test and t couple and Exact Fisher test) were used.

\section{Results}

In this study, the obtained data extracted out of 94 study samples, including 47 in the control group and 47 in the intervention group were analyzed. More than $80 \%$ of the study subjects were married. Most of them in both groups were housewives. The study subjects' demographics revealed no significant difference between two groups (Table 1). The majority of the patients in the two groups suffered from bipolar disorder.

The mean scores of the different domains of "quality of life" were also compared between 2 groups. Based on Table 2, two groups of control and intervention have exhibited no post-intervention significant difference in the domains except for the physical functioning in the two main domains and the general state of the quality of life so that the mean post-intervention score of the intervention group was more than that of the control group. No significant difference was observed between control and intervention group $(\mathrm{P}=$

Table 1. Distribution of demographic variables in 2 groups of caregivers $(n=94)$

\begin{tabular}{|c|c|c|c|c|}
\hline & \multirow{2}{*}{ Variable } & Control & Intervention & \multirow{2}{*}{ Test Result } \\
\hline & & No. (\%) & No. (\%) & \\
\hline \multirow{4}{*}{ Age, year } & $<35$ & $13(27.7)$ & $13(27.7)$ & \multirow{4}{*}{$0.193^{*}$} \\
\hline & $35-45$ & $14(29.8)$ & $8(17.0)$ & \\
\hline & $45-55$ & $11(23.4)$ & $20(426)$ & \\
\hline & $<55$ & $9(19.1)$ & $6(12.8)$ & \\
\hline \multirow{2}{*}{ Gender } & Female & $31(66.0)$ & $28(59.6)$ & \multirow{2}{*}{$0.410 * * *$} \\
\hline & Male & $16(34.0)$ & 19(40.4) & \\
\hline \multirow{3}{*}{ Marital status } & Single & $3(6.4)$ & $6(12.8)$ & \multirow{3}{*}{$0.610^{* *}$} \\
\hline & Married & $42(89.4)$ & $40(85.1)$ & \\
\hline & Divorced or widowed & $2(4.3)$ & $1(2.1)$ & \\
\hline \multirow{4}{*}{ Job } & Self-employed & 15(31.9) & $15(31.9)$ & \multirow{4}{*}{$0.005^{* *}$} \\
\hline & Employee & $1(2.1)$ & $12(25.5)$ & \\
\hline & Homemaker & $27(57.4)$ & $18(38.3)$ & \\
\hline & Other & $4(8.5)$ & $2(4.3)$ & \\
\hline
\end{tabular}




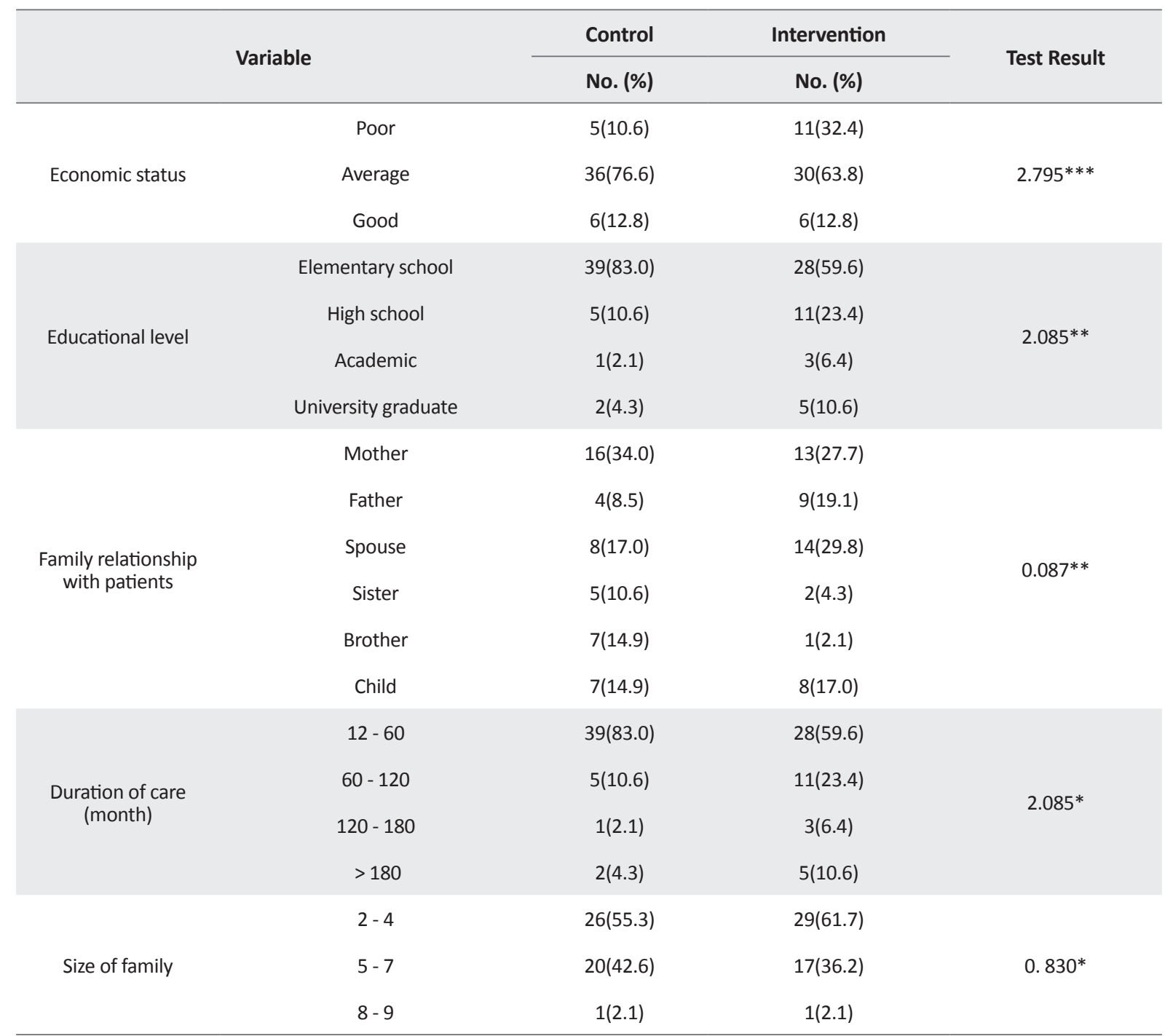

* The T-Test was performed. Client-Centered Nursing Care

** The Fisher exacT-Test was performed.

*** The Chi-Square test was performed.

0.837 ) with regard to the physical functioning score. However, the mean scores of the intervention group increased in all domains (except in physical functioning domain) after the intervention $(\mathrm{P}<0.001)$.

And finally, it is worth pointing out that he pre-intervention and two months after the intervention related quality of life score variation in the intervention group has been statistically meaningful compared with that of the control group and positive in the intervention group $(\mathrm{P}<0.001)$. It should be noted that increase in various quality of life dimensions in the intervention group when being discharged compared with their scores before the training intervention. Although this increase was also seen in the control group, comparing the variations between two groups revealed that this rise in the intervention group was higher and can be attributed to the effect of training (Tables 2 and 3).

\section{Discussion}

The study results indicate that training coping strategies has positive effects on care burden and reduced it. Our study findings are compatible with those of the previous studies. A study reported that caregivers might experience high burden. Factors that led to high burden were the low income of caregivers, having to cope with work and taking care of persons with schizophrenia, care giving over long periods, increasing age of caregivers, and lack of resources for caregivers. Factors that lower the burden were also examined, including personal positive coping skills of the caregivers, family involvement 
Table 2. Comparison of the mean of different domains of quality of life in the control group before and after the intervention $(n=47)$

\begin{tabular}{|cccc}
\hline \multicolumn{1}{|c}{ Quality of Life } & $\begin{array}{c}\text { Baseline Assess- } \\
\text { ment }\end{array}$ & $\begin{array}{c}\text { At the End of the } \\
\text { Study }\end{array}$ & Independent T-Test Result \\
\hline Variation & Mean \pm SD & Mean \pm SD & \\
\hline Physical functioning & $75.53 \pm 25.54$ & $75.42 \pm 25.53$ & $t=1.000, \mathrm{df}=46, \mathrm{P}=0.323$ \\
\hline Role playing restriction due to physical problems & $51.06 \pm 42.01$ & $25.00 \pm 28.55$ & $\mathrm{t}=6.064, \mathrm{df}=46, \mathrm{P}<0.001$ \\
\hline Role playing restriction due to emotional problems & $34.75 \pm 40.50$ & $8.51 \pm 22.49$ & $\mathrm{t}=4.987, \mathrm{df}=46, \mathrm{P}<0.001$ \\
\hline Vitality & $43.19 \pm 23.23$ & $26.81 \pm 15.41$ & $\mathrm{t}=6.987, \mathrm{df}=46, \mathrm{P}<0.001$ \\
\hline Mental health & $53.53 \pm 23.55$ & $42.55 \pm 17.04$ & $\mathrm{t}=5.549, \mathrm{df}=46, \mathrm{P}<0.001$ \\
\hline Social functioning & $59.84 \pm 21.80$ & $43.62 \pm 20.00$ & $\mathrm{t}=5.067, \mathrm{df}=46, \mathrm{P}<0.001$ \\
\hline Body pain & $63.46 \pm 25.29$ & $53.24 \pm 22.92$ & $\mathrm{t}=3.749, \mathrm{df}=46, \mathrm{P}<0.001$ \\
\hline Public health & $49.04 \pm 19.52$ & $42.55 \pm 17.53$ & $\mathrm{t}=3.744, \mathrm{df}=46, \mathrm{P}<0.001$ \\
\hline Physical health & $59.77 \pm 20.47$ & $49.05 \pm 15.65$ & $\mathrm{t}=6.591, \mathrm{df}=46, \mathrm{P}<0.001$ \\
\hline Mental health & $47.83 \pm 23.31$ & $30.37 \pm 14.53$ & $\mathrm{t}=7.486, \mathrm{df}=46, \mathrm{P}<0.001$ \\
\hline Quality of life & $53.80 \pm 19.84$ & $39.71 \pm 13.64$ & $\mathrm{t}=7.848, \mathrm{df}=46, \mathrm{P}<0.001$ \\
\hline
\end{tabular}

Client-Centered Nursing Care

Table 3. Comparison of the mean of different domains of quality of life in the intervention group before and after the intervention $(n=47)$

\begin{tabular}{|c|c|c|c|}
\hline Quality of Life & $\begin{array}{c}\text { Baseline Assess- } \\
\text { ment }\end{array}$ & $\begin{array}{l}\text { At the End of the } \\
\text { Study }\end{array}$ & Independent T-Test \\
\hline Variation & Mean \pm SD & Mean \pm SD & \\
\hline Physical functioning & $67.23 \pm 27.02$ & $67.55 \pm 26.84$ & $t=0.156, d f=46, P=0.877$ \\
\hline Role playing restriction due to physical problems & $30.32 \pm 34.55$ & $65.42 \pm 30.64$ & $t=6.833, d f=46, P<0.001$ \\
\hline Role playing restriction due to emotional problems & $26.95 \pm 33.07$ & $62.41 \pm 31.56$ & $t=6.052, d f=46, P<0.001$ \\
\hline Vitality & $35.64 \pm 15.76$ & $57.87 \pm 15.84$ & $t=8.934, d f=46, P<0.001$ \\
\hline Mental health & $46.38 \pm 18.72$ & $61.45 \pm 14.62$ & $t=5.895, d f=46, P<0.001$ \\
\hline Social functioning & $42.82 \pm 22.53$ & $56.91 \pm 19.12$ & $t=5.264, d f=46, P=0.001$ \\
\hline Body pain & $52.82 \pm 28.22$ & $64.47 \pm 24.19$ & $t=4.177, d f=46, P<0.001$ \\
\hline Public health & $43.62 \pm 21.05$ & $55.74 \pm 16.61$ & $\mathrm{t}=4.365, \mathrm{df}=46, \mathrm{P}<0.001$ \\
\hline Physical health & $48.50 \pm 21.18$ & $63.30 \pm 18.08$ & $t=8.678, d f=46, P<0.001$ \\
\hline Mental health & $37.95 \pm 18.19$ & $59.66 \pm 15.20$ & $t=8.658, d f=46, P<0.001$ \\
\hline Quality of life & $43.22 \pm 17.99$ & $61.48 \pm 15.37$ & $t=9.590, d f=46, P<0.001$ \\
\hline
\end{tabular}

Client-Centered Nursing Care

apart from the caregiver, spiritual support, social support, availability of mental health systems, and availability of other resources (Tan et al. 2012).
Also Khajavi et al. (2011) reported that by use of the impact of type of coping strategies on extent of burden sustained to chronic schizophrenic and bipolar caregivers, 
training problem-centered coping strategies to caregivers may be considered as an approach for reducing burden tolerated by caregivers. Caregivers of patients with chronic mental disorder are a specific group with specific demands which must be recognized. As the starting point, supports such as training families, short-term hospitalization, psychiatric and professional rehabilitation and rendering services to patients at home may be pointed out. Also, the burden on them may be reduced by planning medical sessions based on increasing use of problem-centered coping approaches.

The most caregivers of patients with psychiatric illnesses were under stress and use different coping measures to deal with their stresses. This highlight that emotional distress is common among caregivers of patients with mental illnesses. The caregivers play vital role in caring the psychiatric patients whose behaviors are more irritating than other patients which may cause stress in both caregivers and the patients. The finding suggests that various interventions should be applied to the caregivers to reduce their stress level and improve their quality of life (Darlami, Ponnose \& Jose 2015).

The research by Kate et al. (2013) suggested that the caregivers spending more time on the patient experience higher tension. The scope of care burden tension has positive and significant association with avoidance strategy, compatibility, coercion, and total coping checklist score. The relationship between care burden and all life quality domains has been negative and significant. The total general health score has positive and significant relation with care burden tension. In this study, higher scores of tension scope has been attributed to poor life quality of the caregivers. It is possible that problem-oriented coping strategies skills are associated with caregivers' knowledge, information source, mental training, and cognitive capabilities. Thus if these coping skills are inadequate or inappropriate, they may not sufficiently lower the caregivers' experienced stress and burden. Caregiving burden, especially tension is associated with use of maladaptive coping strategies, poor quality of life and higher level of psychological morbidity in caregivers (Kate et al. 2013).

Navidian et al. (2010) reported that group mental training intervention can be an effective and efficient family intervention for family caregivers of mentally ill patients in a sample of Iranian community. Bademli and Çetinkaya (2014) study indicates that the intervention program has a positive impact on the mental health status and coping strategies of caregivers of patients with schizophrenia. In this research, some special variations have been spotted among intervention group after program completion in the effective coping strategies of self-confidence, optimism, following the social support as well as in non-effective coping method in distress method. Concerning the study results, the intervention program has had positive effects on mental health and coping strategies of the caregivers of schizophrenic patients.

Livingston et al. (2013) study showed that in promoting the mental health of caregivers of patients with dementia, $40 \%$ of these caregivers had significant depression or anxiety and this study has been effective in lowering depression and anxiety symptoms of dementia patients' caregivers. Also the caregivers' life quality in the intervention group had significantly increased.

The group mental training intervention had promoted the life quality and social support of caregivers of bipolar patients. But it has left no significant effect on the depth of the relations of the caregivers of bipolar inpatients. It can be concluded from the study results that coping strategies training can lower care burden (Mojarrad, Ghanbari \& Modares 2012). In conclusion, the present study demonstrated that training coping strategies to caregivers has had positive effects and the post-intervention training has resulted in improving their quality of life. According to the findings, the study hypothesis, i.e., "post-intervention quality of life in the intervention group has been higher than that of the control group" is verified. Based on the current research results, training coping strategies can promote the quality of life. Experts in family health education are in need to educate and train families. Therefore the mental health system is recommended to raise quality of life via developing such specialized programs and facilities at educational and health centers.

This study was conducted only on caregivers of patients with chronic mental disorders, and the short time followup might also be considered as a limitation to generalize the findings of this study. Therefore, conducting similar studies with longer follow-up is recommended.

\section{Acknowledgements}

The present research has been adopted from Fahimeh Ramezan MSc. thesis done in 2016. Hereby, we sincerely appreciate the Vice-president of Iran University of Medical Science Research Department for cooperating with us and funding the due research and also we really thank the honored teachers and especially all patients and their caregivers, doctors, nurses, management and staff of Babol based Shahid Yahyanejad and Ayatollah Rouhani Hospitals and all those assisting us in this study. 


\section{Conflict of Interest}

The authors declared no conflict of interests.

\section{References}

A Group of Psychiatry Professors of Medical Universities in Iran, 2010. [Textbook of Clinical Psychiatry and Behavioral Sciences (Persian)], Arjmand, Tehran

Abbasi, A., Shamsizadeh, M., Asayesh, H., et al., 2013. [The relationship between caregiver burdens with coping strategies in family caregivers of cancer patients (Persian)]. Iranian Nursing Scientific Association, 1(3), pp. 62-71.

Bademli, K. \& Duman, Z. Ç., 2014. Effects of a family-to-family support program on the mental health and coping strategies of caregivers of adults with mental illness: A randomized controlled study. Archives of Psychiatric Nursing, 28(6), pp. 392-398. doi: 10.1016/j.apnu.2014.08.011

Boyd, M. A., 2008. Psychiatric nursing: Contemporary practice. Lippincott Williams \& Wilkins, Philadelphia.

Corring, D. J., 2002. Quality of life: Perspectives of people with mental illnesses and family members. Psychiatric Rehabilitation Journal, 25(4), pp. 350-358. doi: 10.1037/h0095002.

Darlami, K., Ponnose, R., \& Jose, P., 2015. Caregivers stress of psychiatric patients. Journal of Universal College of Medical Sciences, 3(2), pp. 39-43. doi: 10.3126/jucms.v3i2.14290

Glozman, J. M., 2004. Quality of life of caregivers. Neuropsychology Review, 14(4), pp. 183-196. doi: 10.1007/s11065-004-8158-5.

Glynn, M., et al., 2000. Family participation in mental health services [K. Malekoti., M. Araste Persian trans.], Iran University of Medical Sciences, Tehran.

Haresabadi, M., et al., 2012. [Family burden in schizophrenia patients admitted to Imam Reza hospital- Bojnoord 2010 (Persian)] Journal of North Khorasan University of Medical Sciences, 4(2), 165 172

Hudson, P., etal., 2008. Evaluation of a psycho-educational group programme for family caregivers in home-based palliative care. Palliative Medicine, 22(3), pp. 270-280. doi: 10.1177/0269216307088187.

Kate, N., et al., 2013. Relationship of caregiver burden with coping strategies, social support, psychological morbidity, and quality of life in the caregivers of schizophrenia. Asian Journal of Psychiatry, 6(5), pp. 380-388. doi: 10.1016/j.ajp.2013.03.014

Keltner, N., \& Debble, S., 2014. Psychiatric nursing. Springer, New York

Khajavi, M., et al., 2011. [The impact of coping strategies on burden of care in chronic schizophrenic patients and caregivers of chronic bipolar patients (Persian)]. Iranian Rehabilitation Journal, 9(2), pp. 26-31

Kooshan, M., \& Vaghei, S., 2012. [Psychiatric nursing (Mental health 1) (Persian)], Andishe-Rafi, Tehran.

Livingston, G., et al., 2013. Clinical effectiveness of a manual based coping strategy programme (START, strategies for relatives) in promoting the mental health of carers of family members with dementia: Pragmatic randomised controlled trial. British Medical Journal, 347(2), pp. 6276. doi: 10.1136/bmj.f6276.

Milbury, K., et al., 2013. Longitudinal associations between caregiver burden and patient and spouse distress in couples coping with lung cancer. Supportive Care in Cancer, 21(9), pp. 2371-9. doi: 10.1007/s00520-013-1795-6.

Mojarrad, K. A. H., Ghanbari, H. A. B. A., \& Modares, G. M., 2012 [The efficacy of group psycho educational interventions in promoting quality of life and quality of relationships on family of patients with bipolar disorders (Persian)]. Behavioral Sciences Research, 10, pp. 114-122.

Montazeri A., Goshtasebi A., Vahdaninia M., Gandek B., 2005. [The short form health survey (SF-36) (Persian)]. Quality of Life Research Journal, 14(3), pp. 875-82

Navidian, A., \& Bahari, F., 2008. Burden experienced by family caregivers of patients with mental disorders. Pakistan Journal of Psychological Research, 23(1-2), pp. 19-28.

Navidian, A., Pahlavanzadeh, S., \& Yazdani, M., 2010. [The effectiveness of family training on family caregivers of inpatients with mental disorders (Persian)]. Iranian Journal of Psychiatry and Clinical Psychology, 16(2), pp. 99-106.

Onga, L., 2008. Helping those who help others. American Journal of Nursing, 108(9), pp. 69-70. doi: 10.1097/01.naj.0000334977.74736. f0.

Pickett-Schenk, S. A., Cook, J. A., \& Laris, A., 2000. Journey of hope program outcomes. Community Mental Health Journal, 36(4), pp. 413-424. doi: 10.1023/a:1001913013197.

Rahgozar, M., et al., 2012. [Application of recurrent events model in determining the risk factors of recurrence of schizophrenia (Persian)]. Razi Journal of Medical Sciences, 19(99), pp. 7-11.

Rani, U., 2012. Coping styles and interventions to reduce psychological distress in care givers for the mentally challenged. Indian Journal of Positive Psychology, 3(3), pp. 281-284.

Sartorius, N., et al., 2010. Families E mental disorders [A. Borjali., B Ajilchi., \& M. Salimi Persian trans.], Arjmand, Tehran.

Taherkhani, H., 2012. [Rehabilitation in psychiatry (Psychiatry and community-based psychosocial rehabilitation principles) (Persian)], Arjmand, Tehran.

Tan, S. C. et al., 2012. Burden and coping strategies experienced by caregivers of persons with schizophrenia in the community. Jour nal of Clinical Nursing, 21(17-18), pp. 2410-2418. doi:10.1111/j.13652702.2012.04174.x

Varcarolis, E. M., 2002. Developing therapeutic relationships. In M. J. Halter (ed.), Foundations of Psychiatric Mental Health Nursing: A Clinical Approach, $4^{\text {th }}$ edn., Springer, New York. 